\title{
ICT and educational (dis)advantage: families, computers and contemporary social and educational inequalities
}

\author{
Lawrence Angus ${ }^{1 \star}$, Ilana Snyder ${ }^{2} \&$ Wendy \\ Sutherland-Smith ${ }^{2}$ \\ ${ }^{1}$ University of Ballarat, Australia; ${ }^{2}$ Monash University, Australia
}

\begin{abstract}
Because access to new technologies is unequally distributed, there has been considerable debate about the growing gap between the so-called information-rich and information-poor. Such concerns have led to high-profile information technology policy initiatives in many countries. In Australia, in an attempt to 'redress the balance between the information rich and poor' by providing 'equal access to the World Wide Web' (Virtual Communities, 2002), the Australian Council of Trade Unions, Virtual Communities (a computer/software distributor) and Primus (an Internet provider) in late 1999 formed an alliance to offer relatively inexpensive computer and Internet access to union members in order to make 'technology affordable for all Australians' (Virtual Communities, 2002). In this paper, we examine four families, one of which had long-term Information and Communication Technologies (ICT) access, and three of which took advantage of the Virtual Communities offer to get home computer and Internet access for the first time. We examine their engagement with ICT and suggest that previously disadvantaged family members are not particularly advantaged by their access to ICT.
\end{abstract}

\section{Introduction}

Because access to new technologies is unequally distributed, there has been considerable debate about the growing gap, the 'digital divide', between the information-rich and information-poor (Haywood, 1998; Bolt \& Crawford 2000; Compaine, 2001). In an attempt to 'redress the balance between the information rich and poor' by providing 'equal access to the World Wide Web' (Virtual Communities, 2002), the Australian Council of Trade Unions (ACTU), Virtual Communities (a computer/software distributor) and Primus (an Internet provider) in late 1999 formed an alliance to offer relatively inexpensive computer and Internet access to union members in order to make 'technology affordable for all Australians' (Virtual Communities, 2002). This paper examines the social circumstances of four families who accepted the Virtual Communities offer and acquired relatively lowcost computers for use in their homes. Although the sample is very small, the study

\footnotetext{
*School of Education, University of Ballarat, Ballarat 3353, Australia. Email: 1.angus@ballarat.edu.au
} 
indicates that previously disadvantaged family members are not particularly advantaged by their access to Information and Communication Technologies (ICT).

We acknowledge that 'family' can be defined in many ways. For this paper, we are talking about four quite conventional nuclear families. Our aim was to find out how ICT were used formally and informally in both school and home settings. We wished to examine the nexus between students' use of ICT in the home, referred to by Sefton-Green (2001, p. 164) as 'the digital bedroom', and the school. We wish to contribute to broad discussion about whether information technology can be used to 'empower the information disadvantaged' (Compaine, 2001, p. 11) and thereby make a difference to 'the digital underclass' (Bell, 2001, p. 13).

It has long been assumed that families and family life have been affected over time by the various waves of 'new' media such as radio, television, video recorders, computers, multimedia and the Internet (Van Rompaey et al., 2002). The extent of use of relatively new information and communication technologies, for example, has been linked particularly with socio-economic status (SES) and education levels (Livingstone, 1999), although gender is also said to influence uptake of ICT in that men are likely to make the decisions to purchase the hardware and use it (Hellman, 1996). It also appears that when and if a family does decide to purchase new ICT, 'it anticipates the effects that [such purchase] is likely to have on family life and the question of what is likely to be best for the children, in order to help prepare them for future careers and workplaces' (Van Rompaey et al., 2002, p. 190). It is also held that the 'rapid diffusion and uptake of the Internet has been phenomenal' (Holloway, 2002, p. 51) compared with earlier media technologies such as telephone and television. In its latest survey on this matter in February 2001, the Australian Bureau of Statistics (2001) estimated that, in Australia, computer usage is increasing in all socio-economic sectors to the point where almost one-half of all households had Internet access (Australian Bureau of Statistics, 2001).

The rate and extent of uptake of ICT are said to be related to the bursting 'new economies', which are forms of 'knowledge economy' that are related to the 'information society'. Indeed, so strong is the 'rhetoric of inevitability' (Facer et al., 2001, p. 92) associated with the information age that Lacroix and Tremblay (In Facer et al., 2001, p. 92) conclude: 'It is as if there were only two possible kinds of future societies: information societies (the most modern and avant-garde) and the others, those that did not bite the information bullet and which will be condemned to underdevelopment'. For governments, biting the information bullet has included promotion of educational policies in which educational institutions become 'core institutions of capitalism' (Garnham, 2000, p. 142) in order that the nation will remain, or become, internationally competitive in the global knowledge economy. According to this line of argument, the children of the digital generation must be given access to the 'information' in order to be future workers in the knowledge economy (Facer et al., 2001). So there are two particular concerns in countries like Australia about the 'digital divide': first, that people without access to the new technologies will not be part of the new economy/knowledge economy/information age and will be left behind; and second, that people will need ICT access and skills in the new economy in order for the nation to be internationally competitive. 
There is a minority view that the futuristic vision of the burgeoning information society and knowledge economy 'bears little, if any relation, to any concretely and graspable reality' and therefore serves as an 'ideology' (Garnham, 2000, p. 140). Garnham (2000, p. 140) claims that 'rather than serving to enhance our understanding of the world in which we live, [such terms as 'information society' are] used to elicit uncritical assent to whatever dubious proposition is being put forward beneath [their] protective umbrella'. The importance of young people being ICT literate, which is put forward in this perspective/ideology as inevitable, necessary and exciting, is therefore seen by critics like Garnham (2000) to be either simply hype or the assertion of particular capital interests. In criticising the hype, the view is sometimes put that the 'digital divide' is not worth worrying about because it will soon heal itself since the technology, which is already spreading at a furious rate, is becoming increasingly cheap, efficient and easily available (Compaine, 2001). In terms of economic and political interests, the arguments are more complex. The central point is the claim that increasing the availability of and access to ICT and the Internet will not solve the problems of the digital divide because the divide is caused by reasons of differences of culture, education, literacy, opportunity and social power as much as by gaps in ownership of hardware and software. The divide, in other words, is closely related to the same socio-political divide that has long influenced the nature and quality of people's access to education, health services, wealth and power (Griffin, 2000, p. 30). The Internet and ICT are socially constructed. Information technology, and the educational potential of computer education, therefore, should, as Selwyn (2002, p. 429) points out, be regarded as sites of power. This is broadly the perspective that informs this paper.

\section{Methodology}

The research methodology was qualitative. We conducted case studies of four families (three who gained computer and Internet access for the first time under the ACTU/Virtual Communities scheme, and one family that had had access for five years) who had been contacted by the President of the ACTU and who agreed to participate. As it turned out, only two of the four families could be described as clearly 'disadvantaged'. However, the similarities and differences among the four families provided us with rich sources of data upon which to draw in our analysis and interpretation of the effects of ICT in the families. Members of the research team visited each family a minimum of six times in their homes between mid-2000 and mid-2001. Family members were interviewed individually and together, and were observed using ICT. Additional interviews were conducted in parents' workplaces where appropriate. More than 70 interviews were conducted with family members. The schools the children attended were visited at least three times and the children were observed in various classes using computers. The research team also interviewed their teachers, the principal or assistant principal of the school, computer coordinators, English teachers and curriculum coordinators. Altogether there were over 100 interviews. Policy documents and school charters were viewed to help 
us understand the 'mission statements' of the schools in providing computer technology. Two primary and two secondary schools were included in the study.

\section{The participating families}

Sketches of the four families as they were in 2000-2001 are presented in the following.

\section{The Rodriguez family}

Fernando and Luisa Rodriguez are political refugees from Chile. They came to Australia in 1988 and now live in a new housing estate in the outer-eastern Melbourne suburb of Blue Hills. Fernando is a metal worker in a factory and Luisa is a childcare worker in a crèche. They have two children, Carmen, aged 11, who attends St Cecilia's Catholic Primary school in a suburb $15 \mathrm{~km}$ from Blue Hills, and Lydia, aged 5, who is in the pre-kindergarten group at the childcare centre where Luisa works. Both children are bilingual. Spanish is the language spoken at home.

Fernando explains: 'Most of my English is factory English, you know?'. He did not complete secondary schooling in Chile and has not attempted any study in Australia. Nonetheless, he badly wants his daughters to succeed in their education. Fernando does not use a computer at work, and says he uses the computer at home for e-mailing people in Chile, accessing Chilean news websites, and following Chilean soccer results. He bought the computer through the Amalgamated Metal Workers' Union for his daughters to use primarily for educational purposes. 'Computer is everything now', he says. He is not adroit with the keyboard and has to think before finding the functions he needs. As the family never sits around the computer together (unlike the Browns and the Lakes, whom we discuss later), Fernando has to call either Luisa or Carmen to show him how to do things. During an interview with Carmen, the following exchange occurred:

[Fernando comes in and looks on and smiles. He appears proud that Carmen is so competent on the computer]

Fernando: You see? [gesturing that Carmen is operating various functions]

Interviewer: Very quick. [indicating to Fernando that Carmen knows her way round the keyboard and is not fumbling keys]

[Fernando laughs and gestures that he is not at all competent on the computer. $\mathrm{He}$ throws up his hands.]

The logbook that the family kept over a three-week period had no entries to indicate Fernando had used the computer during that time.

Luisa studied French at school and completed her secondary education in Chile. In Australia, she has taken Migrant English classes and completed Technical and Further Education studies in childcare. She uses a computer in the crèche she runs, including using the Internet to search for specific information (e.g. about Rubella). She says: 'Everything computer is new for me ... But if I want to communicate with 
my daughter I have to know about this, and I'm supposed to know more than her-because I'm the mother. I still believe that mums should know more'. She and Fernando say they seek 'excellence' in education, which is why they are prepared to pay fees and send Carmen to a Catholic girls' school so far away from home.

Carmen would like to become a veterinary surgeon and both parents are keen that she pursues this goal. She is a hard worker at school and the family rule is that she is permitted to use the computer only on Friday nights and weekends. She must finish her homework on other nights. She is able to demonstrate how she accesses the Internet, using the dedicated key on the Internet keyboard. She borrows CD-ROMs from the school library and uses the computer to listen to music, or she goes onto the Internet to use e-mail. She shows a picture she constructed using Crayola that she calls 'Lazy Days'-explaining that it's what she sees when she lies down: 'a river and background and other things'. She also borrows books from the library and is reading Hitler's Daughter.

\section{The Brown family}

Jenny Brown is a single mother living on benefit payments and raising her two children, Brad, aged 14, in Year 9 and Lizzie, aged 12, in Year 7. They live in a modest council house in Greenacres, a suburb in northwestern Melbourne about 12 $\mathrm{km}$ from the central business district. Both children attend Greenacres Secondary College. Jenny turned 32 in 2000. She did not complete secondary school and has never had a job. Her father, who retired from the Vehicle Builders' Union in 1999, took advantage of the Virtual Communities offer and leased a computer package for himself and one for Jenny and her children. The computer and the television are in the 'lounge room'. During our visits, both were always on.

Brad and Lizzie have no contact with their biological father who walked out on Jenny two weeks after Lizzie was born. They regard Tony, with whom Jenny had a de facto relationship for almost 10 years, as their dad. Jenny's father says his motivation for leasing the computer package was to provide his grandchildren with another source of entertainment and amusement. Jenny says she is interested in its educational benefits for Brad and Lizzie: 'I mean, they're the future and they're gonna take over everywhere and so it was like, well, it will definitely help them look up things'.

All three use the computer to go to chat rooms: all three say how they enjoy meeting people from a range of countries, backgrounds and different ages. When asked how they determine whether the person to whom they are speaking is being truthful, all say confidently that it is easy to tell. Lizzie illustrates:

One guy goes: 'Oh I'm 16. How old are you?'. I go: 'I'm 12', and he goes: 'Oh, I'm 12 too'. I go: 'Why did ya say you were 16 then?'. So he goes: 'So people would accept me and talk to me'.

Lizzie says she can tell someone's age by the way they 'speak' in chat sites: 'He just talks like, more adulty, instead of little kid talk sort of thing'. Brad adds: 'You find 
little kids blow kisses to each other and that sort of thing, whereas adults don't'. Jenny adds: 'Kids say things like "What's up?" and just different things'.

Jenny says she can quickly tell if people are not what they 'say' they are:

There are ones that you don't trust and you'd more or less pick that up as soon as they say hello to you, just from different things they say, so it's normally: 'All right, thank you very much, goodbye, gotta go'. Whereas the others, I mean, the others you can be picky and choosy and it's like, 'no, speak to someone that sounds a little more genuine'.

When asked how she supervises her children in these situations, Jenny says:

Oh yeah, we sit there often and actually watch each other and 'have a look at this one' and like, 'yep, this one, you know straight away he's going to be a right sleeze'; and yep, 'ta ta, alright, see ya later'. We just close, that's what we do.

Lizzie adds:

A couple of times, I've seen like these people come up to me and they go: 'Oh hello'. And I go: 'Oh hi'. And they go: 'Do you wanna cyber [have cyber-sex]?' and I go: 'No, I'm only 12'. And they go: 'Oh you're old enough'. And I go: 'No! I'm not'.

Jenny sighs:

They ask all the time, all the time, male and female, it doesn't matter. I mean you have people click on ya and you know straight away they're the people, you know just straight away, 'no thank you, goodbye'.

While someone in the family is using the Internet, someone else is watching television or playing with the Play Station. If Brad wants to listen to music that he has downloaded from the Internet, he goes to his room and uses headphones.

Jenny claims the computer has 'changed our life'. The virtual world of chat has become her social focus and she relishes the friendships and relationships that have developed from it. She says: 'I feel like I've got friends on the computer. There's friends I can talk to, have a laugh with'. Jenny had been almost housebound for years-just going shopping at the local supermarket is a major expedition, as both kids have to assist and carry as many bags as they can. Now, after being energized by having friends 'in the computer' after years of 'feeling like a nothing', Jenny is talking for the first time about getting a job: 'I mean, you start evaluating, like, what have I been doing with meself and what am I going to do? It's amazing what chatlines can do!'.

Lizzie Brown wants to be a clothes designer. Her teachers describe her as quite skilled with technology, but a rather quiet and shy student. Various teachers describe her as 'a nice kid', 'quiet', 'probably below average' and 'a pleasant student who needs to be helped'. Lizzie wishes teachers would 'just to stop tellin me off'. At home, she uses the computer for e-mail, plays on Internet sites such as Virtual Dog, Barbie.com and fan sites, and uses chatrooms a lot. She is very competent in the chatroom environment and has created images of herself (avatars) that represent her physically in the virtual world.

Brad Brown 'hates school'. He says: 'I hate wakin up for it. I hate goin to it. I hate comin home and havin to work for it ... just everyfin about it. I just hate everyfin about school'. Although Greenacres Secondary College is a big school, Brad is 
described as the sort of student 'every teacher knows'. He was 'kept down' at the end of Year 7 and made to repeat. Failing Year 7 is very rare, even in schools like Greenacres that have a relatively low level of academic success. But despite being perceived as 'a loser' and as a serious discipline problem by teachers, Brad is highly competent with the computer at home. He is the one relied upon by Jenny and Lizzie to troubleshoot when the computer breaks down. He says: 'When somefin happens, I know straight away basically'. He says he uses the computer for everything: 'I just go on it, muck around, talk to my friends, get car pictures, download songs-I do everyfin on it'. He also accesses sites for job searches and uses e-mail and chatroom functions. In contrast to his home use of computer technology, Brad asserts: 'I didn't learn nuthin at school from the computer'. Then reconsidering: 'I had infotech classes and I gotta admit I learnt somethin but I've never used it-mailmerge!'

\section{The Lawford family}

Helen and Brendan Lawford are recently divorced. Brendan is a communications manager for a large union and Helen is a corporate assessor for a multinational power and resources company. Both had been actively involved in union activities during university days prior to Helen being employed as a bureaucrat in public sector administration in Victoria in the late 1980s and early 1990s. With a change in political power in 1992, Helen moved easily to a higher-paid position in the private sector. Brendan hints that the strain in their marriage may have been partly due to his perception of a change in Helen's political values. Brendan still works for the union and is committed to the cause. The couple have a six-year-old daughter, Angela, who is in Grade 1 at the inner-city Rosewood Primary School. Angela lives with Helen in the family home (which houses the computer from Virtual Communities), and her father has a flat nearby where Angela stays two nights a week.

Helen has an unusual background for such a corporate high flier-quite similar in fact to that of Jenny Brown. Helen's parents were among the wave of British immigrants in the 1950s who settled in a brand new satellite city just north of Adelaide, near other working-class suburbs like Happy Valley and Paradise. Few of the kids who attended schools like Satellite High in the 1970s completed their secondary schooling, much less went on to higher education. Helen did both. She recalls a major defining moment in her life-what she calls her 'Big W experience', which occurred when she had been working during the summer school holidays at a large 'Big W' supermarket where she must have impressed her superiors. At 15, she was offered full-time, continuing work at the store-an offer most of her friends would have jumped at. The offer caused her to seriously consider where she was headed. She talked it over with her parents and recalls thinking: 'I'm fifteen and not pregnant. Perhaps I might amount to something!'.

Brendan and Helen both have jobs that demand a high degree of computer competency; both regard the computer as an integral part of Angela's education. They bought her first computer program when she was four years old because it was 'the best little program around and it was all about mouse skills'. It is apparent that 
six-year-old Angela is highly computer literate and competent. She observes: 'The fun things are where you go somewhere and you see all these addresses ... on the train, in the car, and I put them in my head and when I come home I go to the computer and I search them'. Helen says: 'I know she's learning; when she thinks she's playing [on the computer] I know she's learning'. At the same time, both parents emphasize the importance of books. Helen insists that Angela 'is a very, very good reader and reads at above average levels'.

\section{The Lake family}

The Lake family live in the inner-city suburb of Kilvington and the two girls, Felicity, aged 15, in Year 11 and Sally, aged 13, in Year 9, attend City High School. Sara and Ray Lake both have postgraduate degrees (arts, management and labour relations law for Ray; arts and law for Sara) and hold senior trade union positions. They initially bought a computer so they could work at home, and for the girls' schoolwork. The family members see the computer as a tool for work or research but stress the superiority of books and their love of the world of paper-text. For instance, during family discussions around the dining table, at which family members linger after meals, someone will often reach for the Encyclopedia Britannica to settle a dispute or look up information relevant to dinner-table conversation. While actively downplaying the importance of the computer and their ICT skills in general (Ray: 'I'm never sure where to put the petrol in'), all members of the family are exceptionally competent technology users.

Felicity is a member of a band that meets on weekends and finds that Hotmail is very useful for making arrangements. Sally has used computers at school from an early age and enjoys games and e-mailing friends. She says she's good at Internet searches and downloads images for projects but, when asked about how much she uses the Internet for research purposes, she gestures to the Britannica volumes on the shelf behind her to indicate that she more often refers to them. In fact, the status of the Encyclopedia Britannica in the house has become something of a family joke:

Felicity: The other day I was looking up old song lyrics [on the Net] but I usually just go to the library or into the dining room ...

Interviewer: And get the Britannica out.

Felicity: Yeah!

The favourite family computer activity is playing Civilisation. Sally describes it as 'a particularly addictive game' and adds: 'Sadly, this is what I do most of the time'. She likes to play the part of 'someone like Catherine the Great, but called Bob-easier to remember'. The family consider this game feeds their love of history and culture.

\section{The families, cultural resources and relationships with school}

In examining the attitudes of the participating families to the use of computer technology at home and school, we find it useful to consider the concepts of cultural 
access and deprivation, and the relationship between processes of advantaging and disadvantaging. Bourdieu (1990) considers that 'capital', the kinds of resources that can give one social and economic advantage, can be of different forms. There are tangible forms of durable capital, such as money and quantifiable assets, which he terms 'economic capital'. There are also non-material forms of capital, called 'symbolic capital'. These forms of capital enable individuals who possess them to open or close doors to material success and power. One form of symbolic capital is social capital, which Bourdieu (1990, p. 35) defines as 'a network of kinship (or other) relations capable of being mobilized or at least manifested'. For example, Jenny Brown says her life has been 'changed by the computer' as her social network, which confers upon her greater confidence and self-esteem than she has felt for many years, is now that of Internet chatrooms where she feels she is a valued member. The final type of symbolic capital, and the main one we use in this discussion, is Bourdieu's (1990) notion of 'cultural capital'.

Cultural capital includes all the attributes, including education, literacy and social graces, with which an individual is endowed. An example of cultural capital is the desire of some of the parents (Lake, Lawford and Rodriguez families) that their children attain 'excellence' in education. In the case of the Lakes and the Lawfords, this expectation would seem realistic enough. Indeed, although we must emphasize that nothing is pre-ordained about social futures and one cannot with any accuracy predict social and economic success, good educational outcomes would seem a normal and 'natural' consequence of Felicity's, Sally's and Angela's 'inherent' skills, networks and 'insider' knowledge of what counts as education, knowledge and culture. This is all part of their social and cultural identities. Their backgrounds and easy familiarity with the education world (although Helen had to win such familiarity the hard way) enhance their level of cultural capital way above that of the Rodriguez family, in which the parents, particularly Luisa, are striving to enhance their children's cultural opportunities and identities through private education. But the Rodriguez family is in turn way ahead of the Browns in the cultural capital stakes.

All four families acknowledge that the computer is a tool for accessing information that can be processed into knowledge. Such access to knowledge is a form of cultural capital as defined by Bourdieu (1990). All families agree that using computers in the home is of educational benefit to their children. The Lake family, however, prefers the hard copy of Encyclopedia Britannica as a source of information but admits that 'unfortunately, the computer is necessary'. The Rodriguez and Lawford families consider computer skills and technology as one means of opening doors to future higher education and economic sectors. Luisa and Fernando Rodriguez are not such highly skilled users of computer technology as Helen and Brendan Lawford, but they are determined that their daughters will be. For all of them, there seems to be a clearly perceived relationship between computer competence and educational success. Yet the relationship between the schools, the children and the four families is complex and variable.

For example, Angela Lawford quite likes computing classes but is disappointed that 'at school you don't get to choose what you do. They actually show you what 
you're meant to be doing and we're meant to be working on [that]'. Angela spends most time at Barbie.com and sites to do with witches and fairies. She enjoys spelling and number games that could be regarded as school-like. The recreational computer activities of the Lake girls could also be regarded as school-like. As a family, they love playing Civilisation (which accounts for the majority of time spent on the computer) and looking up on the Internet ingredients from interesting restaurant dishes or the botanical names of plants-although their preference is for the hard-copy Britannica. The Brown children, however, derive pleasure from decidedly un-school-like computer activities. Principal among these is chat. There's also music downloading and searching for car information and images (Brad), and celebrity news, magazine and fan sites, and virtual dog (Lizzie). One of the few times Brad spoke with enthusiasm about anything (except his job, which we discuss later) was when he said:

I love the ... when I go on the Internet, well ... yeah, and like, I'll save a few pictures to my file, like car pictures, pictures of cars, and soon as I'm offline or whatever, ya know, I'll go into paint, open file, yeah, and put a car picture. And if, like, I put a car picture, I can like chop the roof off, make it smaller, make the wheels fatter, like modify it. Yeah, it's fun. [laughs]

For all of these young people, as Facer et al. (2001, p. 106) put it:

the active computer user outside school is forced into the position of novice learner within the school environment and, at times, is actively required to 'forget' the skills learnt in the home.

In Brad's case, the response at school to his Internet skills (as we discuss later) was particularly crude and dismissive.

One startling difference between the Brown family and, say, the Lawford family, is the way the families, indeed the school communities, are perceived within their respective schools. Angela Lawford is discussed fondly by her teachers, who are impressed by the level of support she receives from her extended family. Helen knows each of Angela's teachers by their first name. She has harmonious contact with the school, where she feels welcomed, as part of her routine. Jenny Brown, however, asserts: 'the only times I've contacted the school is when [Brad's] in trouble'. She has no rapport with teachers at all. Jenny is an 'outsider' where Helen is a valued 'insider'. This raises issues about how different 'parental voices' (Vincent \& Martin, 2002) are 'heard' and listened to in schools.

Angela's current classroom teacher, Alan West, says: '[Angela's] like the perfect student, the ideal child'. Over at Greenacres Secondary College, however, you cannot find anyone with a very high opinion of Brad or Lizzie Brown. But there is not a high regard for the community either. In response the question, 'how would you describe Greenacres Secondary College', Mr Hall says:

Well, a lot of strugglers. A lot of families that put education well down their list of priorities. Certainly not all. There are parents who do care and who really do try and help the school, but ... I mean we get a lot of animosity no matter what we do from the parents towards the school. 
Even this teacher, who Brad says knows him best, expresses little knowledge of Brad's family: 'They're basically working class stock. Apart from that I really don't know'. The school principal adds: 'for a lot of our kids, the only stable person in their lives who has a values system is their teachers'.

Although we do not develop the point in this paper, the general social and cultural distancing of staff at Brad and Lizzie's school from the social and cultural milieux of the Brown family, and the neighbourhood in general, was quite noticeable, even for teachers who seemed generally 'sympathetic' towards pupils (see also Barber, 2002). The previous quotation indicates not only a systematic discounting of the Browns' (and working class) cultural experiences, but also a teacher view that implies working-class students should endeavour to conform to what McFadden and Munns (2002) call the 'teacher paradigm'. Yet, as they point out, 'because teachers do not solely control the classroom, change cannot be found purely in modifications to their paradigm alone' (p. 361). These authors conclude:

A focus on teaching and pedagogy without reference to the identities and experience that students bring to the pedagogical relationship will always be focussed on one-half of the explanation of and solution to [student] resistance and engagement. (McFadden \& Munns, 2002, p. 361)

Perhaps ironically in this case, there is a view at Greenacres Secondary College that the school's emphasis on technology is precisely to engage working-class students and better equip them for the future. According to the Deputy Principal:

Technology comes number one. It's used as a kind of marketing technique because we give our year $7 \mathrm{~s}$ a really intensive computer program. We make a big thing of the fact that we have four operational computer rooms.

Despite computer education being a 'big thing' for marketing purposes, teachers have very little sense of which or how many students have computers at home; indeed teachers' estimates vary from 'perhaps up to 25 per cent' to 'at least 75 per cent'. The Principal says that schools 'have a corporate responsibility to our kids' and must train students for jobs not yet in existence, particularly 'the acquisition of knowledge and technology'. Technology, it would seem, might be the salvation of the masses.

The general attitude displayed to the working-class community of Greenacres, and to the Brown family in particular, seems consistent with Reay's (2001, p. 335) conclusion that:

In Bourdieurian terms, the working classes both historically and currently are discursively constituted as unknowing, uncritical, tasteless mass from which the middle class draw their distinctions... [by] representing the children of the poor only as a measure of what they lack.

For example, none of the teachers we spoke to knew that Brad or Lizzie had a computer at home. When informed of this fact, one teacher volunteered:

I'm certain that most of the time [Brad's] on the computer he's searching the Net, it's for pleasure not for anything educational. You know the sites that ... Brad's heavily into skateboarding for instance. As a teacher I have a computer at home for my kids. When 
my kids use the computer I like to oversee it and see exactly what they're doing. But who knows what Brad is doing!

Here, within a 'powerful blaming discourse' (Reay, 2001, p. 338), the Browns are constructed as 'others', as being of a different world to the teachers. They and their neighbours are viewed as disconnected from education in ways that the school can say it cannot really do much about.

\section{School work, home computer play and imagined futures}

The Browns contrast with the Lawfords in the ease with which school and home, work and play, are integrated-particularly in terms of information technology. Brendan and Helen Lawford value both computer and traditional forms of literacy highly as part of the cultural capital they wish their daughter to absorb. The fact that Angela Lawford was using her first educational software package at the age of four indicates that her parents are keen for her to become a competent computer user. Brendan has the necessary insider knowledge. He says: 'I knew that the school she was at had computer studies and having some sort of basic click and drag search ability to start with means she's at a level that means she's not going to be behind as soon as they sit down at the screen'. Helen Lawford is equally keen that Angela access paper-text literacy skills. Angela, aged six, has read (with parent assistance) all the Harry Potter books.

The Lawfords articulate the view that playing on the computer is akin to learning computer competence, and are happy about Angela's computer play. Both parents are comfortable with Angela accessing different sites such as Barbie.com. Helen surmises: 'I know that typing out the invitations [for her Barbie.com party] she's learning. As long as I know which sites she's going to, I'm very relaxed about playing'. Jenny Brown also supports the view that a computer at home is important for her children, 'to help them look things up'. The reality is, however, that little schoolwork is done on the computer in the Brown house. It is used particularly for chatroom activities. Although Jenny conceives of computers as 'the future, and they're gonna take over everywhere', she does not insist the computer at home be used for schoolwork, unlike Luisa Rodriguez. In the Rodriguez house, the computer is for education not play.

Luisa and Fernando regard a high level of education, and integration of computer technology into that education, as vital for successful penetration of barriers to cultural and economic power. They explain: 'We want our children to be better than we are'. They are adamant that Carmen and Lydia will obtain better, higher paid jobs than they, themselves, have, and they are fully supportive of Carmen's dream of becoming a veterinary surgeon. Luisa, in particular, regards acquiring knowledge and credentials as vital to improving the life chances of her children. The slightly desperate quest for academic success is putting Carmen under a lot of pressure to avoid failure. It is unlikely that she will ever experience the casual assumption of academic success that pervades the Lake girls' personas. For Felicity and Sally Lake, it would appear (although we repeat our caution that nothing is pre-ordained about 
social futures) that the 'decision' to be successful at school and proceed to university is, as Ball et al. (2002, p. 54) put it, 'a non-decision'. It seems part of a 'normal' and expected social trajectory. For Carmen Rodriguez, it would seem that Luisa has deliberately made a similar decision for her, but this 'active' decision is more problematic. The family lacks the social and cultural resources and supports that are available to the Lawfords and the Lakes.

Unlike Luisa Rodriguez, Jenny Brown is not at all desperate that her children attain high levels of education and thereby increase their cultural capital and their opportunities of acquiring greater economic capital. Yet, perhaps surprisingly, the least hazy 'imagined future' of all the young people is Brad Brown's. From his first interview Brad spoke of his plan to leave school when he turned 15 at the end of 2000 (although he would be only in Year 9) and get an apprenticeship. This was aiming very high in Brad's world (although not so high for the other families) and he was advised at school that such a move would be impossible for him. One teacher said: 'I actually mentioned to him, a lot of times now, you need a minimum of Year 11 for an apprenticeship. Otherwise they're not even going to look at you'. Brad was adamant, however. Once he turned 15 no-one could then make him go back to school. He said he would prove to everyone, including his family, that he could get a job and that he would not conform to the expectation of others that he would become 'a layabout dole bludger'. In the event, Brad did leave school when he turned 15 and has achieved exactly what he said he would achieve. He explains:

The day after [we last spoke] I organised to go up [to the crash repairer's] and we went up there and I spoke to the boss and he said, 'Yeah come in tomorrow and we'll give you a test try'. And I went, 'Oh all right'. And that [next] day they just said, 'Don't worry about the test try, we'll give you an apprenticeship now'.

In terms of where he had set his sights, Brad has achieved huge success against the odds despite bypassing the usual institutional frameworks. Apprenticeships are like gold dust among Brad's peers, even if the work can be dirty and dangerous. He is on track to becoming a skilled tradesperson and, eventually, as Brad sees it, to having his own spray painting or crash repair business. This boy, who was a 'discipline problem', a 'loser' and a 'failure' at school, has been able to use his limited capital-including a rev-head network, an uncle in the automotive trade and Jenny's ex-de facto who is a motorbike fanatic - to make contacts in the business in which he has now scored the kind of apprenticeship of which he always dreamed.

Of the people in the four families, the person who spends most time, by far, on the computer in the home is Jenny Brown. She uses it almost exclusively for chat with a voraciousness that suggests she may be making up for lost time spent with little social contact. This use of Internet chat has enhanced her personal symbolic capital and enabled her, a once socially isolated and housebound woman, to engage with other people and feel pretty good about herself. But it has not so far enhanced her social power. The virtual world of chat and e-mail has become her social capital. Her children have also become engaged in the virtual world of chat, which has a curious relationship to their offline social world. For Jenny in particular, and to a lesser extent Lizzie, the life 'in the computer' is a polished and improved version of 
their 'real' life; an idealized extension of what they do and would like to do, and which, to some extent, fills what is lacking in 'real' life. Their engagement in this partial, virtual world is active, creative and complex, and requires imagination and the making of multiple judgements as cyber relationships and situations are negotiated. Much time is spent discussing avatars and identities, issues of representation, relationships, realities, emotions and truth. As Webb (2001, p. 562) explains: 'Virtual identities are embodied, sensuously experienced and contingently rhythmic and mobile. If you wish, we write identity through them'. Potentially, the capacity to 'produce' identities, representations and alternative realities in such chat activity, rather than just be consumers of computer games and Web-based information, might become a culturally empowering and enriching activity. But at present, in the Brown household, it looks like just fantasy and escapism.

\section{Conclusion}

Overall, compared with the Lawford and Lake children, and also with the Rodriguez girls, Brad and Lizzie Brown have experienced greater inequalities of access to resources and life chances, making the reproduction of disadvantage, for them, more likely. They have a computer and Internet access in their home, making them part of that rapidly expanding group of the technology 'haves', but that is where the similarities with the other children in the study more or less begin and end. We need to ask, therefore, how useful it is to talk about technology 'haves' and 'have-nots'. Our data suggest that we require an expanded, reconceptualized understanding of 'access' and its relation to equity. Access cannot be seen merely as having an Internet connection, but as a much more complex and multileveled social goal (Burbules \& Callister, 2000). The question is about not only who gets how much of the technology resources, but also who gets the benefits associated with such resources and how much of them (Comber \& Green, 1999).

Some time ago Lipkin wrote of new technologies:

Them that has, gets ... If a particular race, sex or economic group occupies an inferior position in society, you only have to be able to add one and one to see that technology will compound the problem. (Cited in Zakariya, 1984, p. 29)

It seems that old inequalities have not disappeared in the increasingly networked society, but neither are they the same nor have they been simply added to. All the families in the study have home access to the Internet so, in the parlance, they are all part of the technology 'haves'. But when compared with the other three families, the Browns are simply not as well off as the others despite Brad's success in gaining an apprenticeship. And the engagement with technology and the social world of the Rodriguez family, regardless of equal access to ICT, is clearly different to that of the Lawfords and the Lakes. We have attempted to capture and illustrate a portion of the complexity of contemporary social and educational inequalities within and across the lives of some young people and their families. It does not seem to us that equal access to ICT, without attention to other socio-political aspects of advantage and disadvantage, will do much to close the digital or social divide. 


\section{Acknowledgements}

The authors wish to acknowledge that this research was supported by an Australian Research Council grant. They thank Lisa Phillips who worked with them in the early stages of the project.

\section{Note}

This is a revised and extended version of a paper first presented at the Oxford Ethnography Conference at the Department of Education Studies, University of Oxford, September 2002.

\section{References}

Australian Bureau of Statistics (2001) AusStats 8147.0 Use of the Internet by householders, Australia. Available online at: http://www.abs.gov.au/Ausstats/ABS (accessed 16 August 2002).

Ball, S. J., Davies, J., David, M. \& Reay, D. (2002) 'Classification' and 'judgement': social class and the 'cognitive structures' of choice of higher education, British fournal of Sociology of Education, 23(1), 51-72.

Barber, T. (2002) 'A special duty of care': exploring the narration and experience of teacher caring, British fournal of Sociology of Education, 23(3), 383-395.

Bell, D. (2001) An introduction to cybercultures (London, Routledge).

Bolt, D. \& Crawford, R. (2000) Digital divide: computers and our children's future (New York, TV Books).

Bourdieu, P. (1990) The logic of practice (R. Nice, Trans.) (Stanford, CA, Stanford University Press).

Burbules, N.C. \& Callister, T. (2000) Watch IT: the risks and promises of information technologies for education (Boulder, CO, Westview Press).

Comber, B. \& Green, B. (1999) Information technology, literacy and educational disadvantage research and development. Project Report to DETE SA (vol. 1) (Adelaide, University of South Australia).

Compain, B. (2001) The digital divide: facing a crisis or creating a myth? (Cambridge, MA, MIT Press).

Facer, K., Furlong, J., Furlong, R. \& Sutherland, R. (2001) Constructing the child computer user: from public policy to private practices, British fournal of Sociology of Education, 22(1), 91-108.

Garnham, N. (2000) 'Information society' as theory or ideology, Information, Communication and Society, 3(2), 139-152.

Griffin, M. (2000) Digital divide, Sydney Morning Herald e-mag, 4 May, pp. 26-30.

Haywood, T. (1998) Info-rich-info-poor: access and exchange in the global information society (London, Bowker Saur).

Hellman, H. (1996) A toy for the boys only? Reconsidering the gender effects of video technology, European fournal of Communication, 11(1), 5-32.

Holloway, D. (2002) Disparities in Internet access: a case study of western Sydney, Australian fournal of Social Issues, 37(1), 51-69.

Livingstone, S. (1999) Personal computers in the home: what do they mean for children? Intermedia, 27(2), 4-6.

McFadden, M. \& Munns, G. (2002) Student engagement and the social relations of pedagogy, British Fournal of Sociology of Education, 23(3), 357-366.

Reay, D. (2001) Finding or losing yourself?: working-class relationships to education, fournal of Education Policy, 16(4), 333-346.

Sefton-Green, J. (2001) The 'end of school' or just 'out of school'?: ICT, the home and digital 
cultures, in: C. Durrant \& C. Beavis (Eds) P(ICT) ures of English: teachers, learners and technology (Kent Town, Wakefield Press), 162-175.

Selwyn, N. (2002) Learning to love the micro: the discursive construction of 'educational' computing in the UK, British Fournal of Sociology of Education, 23(2), 427-443.

Van Rompaey, V., Roe, K. \& Struys, K. (2002) Children's influence on Internet access at home, Information, Communication and Society, 5(2), 189-206.

Vincent, C. \& Martin, J. (2002) Class, culture and agency: researching parental voice, Interchange, 23(1), 109-128.

Virtual Communities (2002) About us. Available online at: http://www.virtualcommunities. com.au (accessed 18 August 2002).

Webb, S. (2001) Avatar culture: narrative, power and identity in virtual world environments, Information, Communication and Society, 4(4), 560-594.

Zakariya, S. (1984) In school (as elsewhere), the rich get computers, the poor get poorer, American School Board fournal, March, 29-32. 